Green brei and cytochrome c, because ascorbic acid could be a direct substrate of cytochrome c. Thus the following experiments were carried out in which the influence of adrenaline was observed by estimating the amount of reduced ascorbic acid remaining.

As shown in Table 4, it was demonstrated that ascorbic oxidation was inhibited by addition of adrenaline and not by preincubated adrenaline.

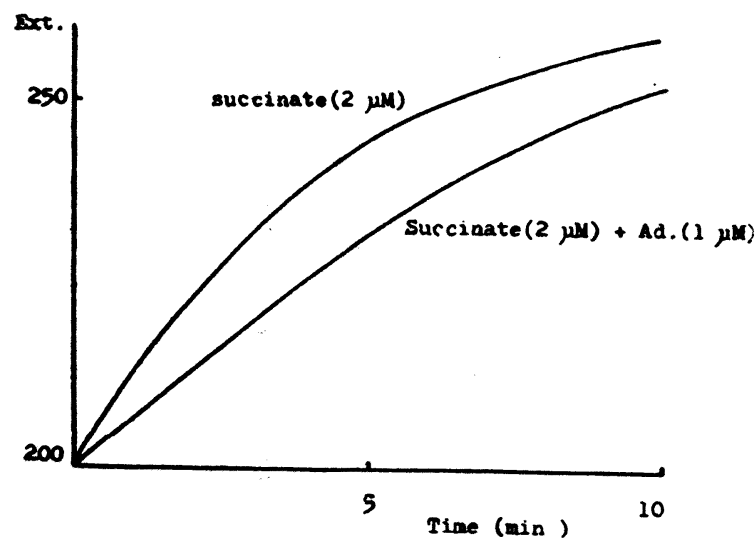

FIG. 5. Influence of adrenaline on the formation of reduced cytochrome $\mathrm{c}$ in succinic oxidation by Green brei.
7) The influence of adrenaline on reduced cytochrome $c$ formation in succinic oxidation

Reduced cytochrome $\mathrm{c}$ formation in succinic oxidation by Green brei and cytochrome $\mathrm{c}$ was followed spectrophotometrically and Fig. 5 illustrated that the presence of adrenaline inhibited reduced cytochrome $\mathrm{c}$ formation in succinic oxidation system.

\section{DISCUSSION}

It was observed in the experiments using homogenates and mitochondria that adrenaline may inhibit the oxidation of intermediates of the TCA cycle in cytochrome respiration, but not in methylene blue respiration. Similar results were also shown in the experiments using three dehydrogenase systems contained in the TCA cycle. Each electron transfer system of these three dehydrogenase systems is differed from one to another and may be summarized as follows according to the recent studies (10-13).

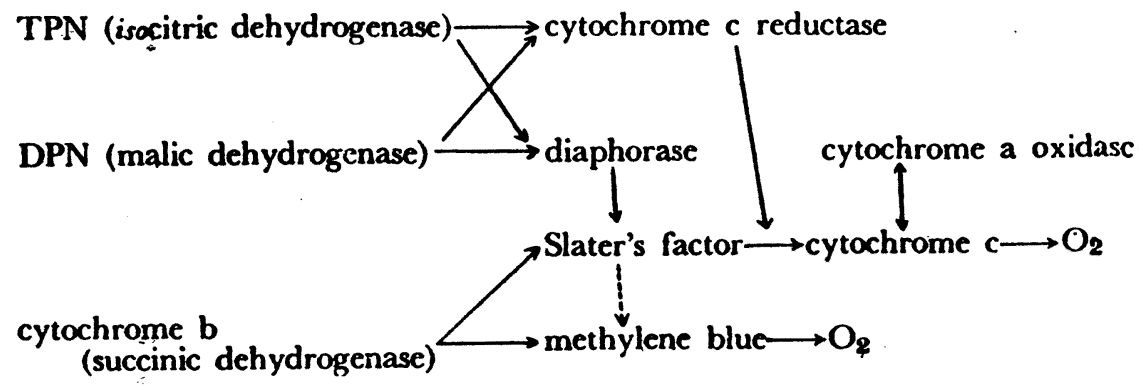

From this scheme and the results described above it was presumed that adrenaline may inhibit cytochrome $\mathrm{c}$ or cytochrome c oxidase. But the fact that the $-\mathrm{OH}$ group of adrenaline could be oxidized by cytochrome $c$, suggested a possible competitive inhibition of adrenaline for the socalled physiological reducing factors, viz. reduced Slater's factor or reduced FAD.

The following experimental results may support this presumption.

(1) A similar inhibitory action of adrenalone and hydroquinone to adrenaline in terms of hydrogen donor was observed but not of ephedrine. 
(2) An inhibitory action of oxidized form of adrenaline was not shown.

(3) Ascorbic acid oxidation by cytochrome $c$ and cytochrome c oxidase was inhibited by the presence of added adrenaline.

(4) Reduced cytochrome $\mathrm{c}$ formation in succinic oxidation was inhibited by addition of adrenaline.

That is, the inhibitory action of adrenaline on cytochrome c reduction became an important problem.

From the above experimental results, it seems likely that the inhibition of the $-\mathrm{OH}$ group of adrenaline is due to its effect on the oxidoreduction of cytochrome $\mathrm{c}$ in physiological electron transfer system. And it appears to be possible that adrenaline formed a complex with cytochrome $\mathrm{c}$ resulting in a decreased reduction ratio of cytochrome $\mathrm{c}$ below the level of physiological electron transportation, while the effect of adrenaline on cytochrome oxidase could be disregarded from the fact that its inhibition was not shown by oxidizing the $-\mathrm{OH}$ group of this compound. Therefore, a possible explanation for the accumulations of lactate and pyruvate following the injection of adrenaline might be given as follows:

The competitive inhibition of adrenaline on cytochrome $\mathrm{c}$ reflects in an unsmooth electron transportation, in addition to the acceleration of anaerobic glycolysis by adrenaline which has been studied in detail by Sutherland.

\section{SUMMARY}

1. Addition of adrenaline inhibited the oxidation of intermediates of the TCA cycle in ordinary respiration, but not in methylene blue respiration.

2. One of the inhibitory effects of adrenaline is due to reducing cytochrome c formation in respiratory chain.

\section{REFERENCES}

1) ARthur, M. AND Fishberg, M.D.: Hypertension and Nephritis. IV, 594-721, Lea and Febiger, Philadelphia (1947)

2) Sutherland, E.W. AND CORI, C.F.: J. biol. Chem. 188, 531 (1951)

3) SChNEIDER, W.C. AND HOGEBOOM, G.H.: Biochem. J. 39, 289 (1945)

4) Green, D.E. AND BrosteauX, J.: Ibid. 30, 1489 (1936)

5) KeIl.IN, D. AND HaRTREe, E.F.: Ibid. 39, 289 (1945)

6) FUJII, Y.: Seikagaku-jikkenho (Japanese) 204-205, Nanzando, Tokyo (1950)

7) SLATER, E.C.: Biochem. J. 4., 14 (1949)

8) Gale, E.F. AND Stephenson, M.: Ibid. 33, 1245 (1939)

9) SLATER, E.C.: Ibid. 44, 48 (1949)

10) HAAS, E., HoReCKer, B.L. AND HgNeSS, T.R.: J. biol. Chem. 142, 835 (1942)

11) Slater, E.C.: Biochem. J. 15, 1 (1949)

12) KUn, E.: Proc. Soc. exper. biol. \& Med. 77, 441 (1951)

13) HoreCKer, B.L.: J. biol. Chem. 183, 593 (1950) 


\title{
THE EFFECTS OF DRUGS ON THE MEMBRANE ACTIVITIES OF THE TOAD SARTORIUS MUSCLE
}

\author{
MOTOHATSU MATSUMURA AND AKIRA YANAI \\ Department of Pharmacology, Faculty of Medicine, Kyoto University, Kyoto \\ Received for publication March 18, 1957
}

\begin{abstract}
Recently, using an intracellular recording electrode, the membrane activities of the frog skeletal muscle and the process of neuromuscular transmission have been studied in detail by many workers (1-12).

However, the effects of many drugs on the muscle membrane potential and transmitter action have yet to be studied with this method.

The purpose of the present experiments is to investigate the effects of drugs, such as veratrine, acontitine, guanidine, quinine, caffeine, etc. on the membrane activities of the toad sartorius muscle.
\end{abstract}

\section{METHODS}

Preparation and apparatus: The nerve-sartorius preparation was isolated in the usual way from the Japanese toad and mounted with its deep surface uppermost in the chamber set in a Petri dish. The muscle was immobilized by fixing both ends, which kept it in a stretched condition in order to avoid movement artifact.

The preparation was observed with a binocular microscope 24 power magnification, using transmitted light.

The electrodes for motor nerve stimulation were situated in a separate moist compartment to which the nerve reached via a narrow groove from the muscle chamber.

Stimulation: The stimulating pulse of less than $1 \mathrm{msec}$ duration was generated by thyratron discharge and delivered through an isolation transformer. The electrodes for direct stimulation were hook-shaped $\mathrm{Ag}-\mathrm{AgCl}$ wire electrodes with a diameter of about $0.5 \mathrm{~mm}$ and were placed on the muscle surface at two points about $5 \mathrm{~mm}$ apart and at a right angle to the length of the muscle fibers.

A stimulus which is intended for direct excitation of muscle fiber may still excite a few intramuscular nerve twigs. Hence the muscle was soaked in the Ringer solution containing $d$-tubocurarine chloride $\left(10^{-4}-5 \times 10^{-5}\right)$ for more than 30 minutes before direct stimulation was applied.

Electrode and amplifier: Capillary microelectrodes, of external tip diameter of less than $0.5 \mu$ and filled with $3 \mathrm{M}-\mathrm{KCl}$, were used. A d.c. amplifier with an input cathode follower of low grid current and reduced grid-earth capacity was used. The microelectrode of low resistance $(8 \mathrm{M} Q-20 \mathrm{M} \Omega)$ was selected and held by the arm of a micromanipulator. 
Recording of end-plate potential (e.p.p.): In the sartorius muscle of the Japanese toad, nerve branches could not be followed up for over long distances along the surface of the muscle under the microscope, and they became especially obscured near the end-plate foci. Hence the e.p.p. was recorded by the following procedure. Neuromuscular transmission was blocked in low-sodium solution at the beginning of the experiment, and a recording electrode was brought to the end-plate focus step by step, observing the shape of the response to nerve stimulation. The e.p.p.'s recorded from the same spots were compared before and after a test drug had been added to the bathing solution. Thus the effect of drugs on the e.p.p. was examined in the low-sodium blocked muscle throughout the present experiments. In these cases, however, it was difficult to maintain the resting potential to the initial level for a long period (usually for less than 30 minutes and only occasionally for more than 60 minutes).

Solutions: The normal Ringer solution used had the following composition: $\mathrm{NaCl}, 6.5 \mathrm{~g}$; $\mathrm{KCl}, 0.1 \mathrm{~g}$; $\mathrm{CaCl}_{2}, 0.15 \mathrm{~g}$; $\mathrm{NaHCO}_{3}, 0.2 \mathrm{~g} ; \mathrm{H}_{2} \mathrm{O}, 1000$ c.c. To obtain low-sodium concentration, $4 / 5$ of $\mathrm{NaCl}$ in the normal Ringer solution was replaced by osmotically equivalent sucrose. For calcium-lack experiments, $\mathrm{CaCl}_{2}$ was removed from the normal Ringer solution and the concentration of $\mathrm{KGl}$ was doubled.

To observe the drug action, each drug was added to the Ringer solution in which the muscle was immersed. The concentrations of the drug were expressed in $W / V$ ( $g / c . c$.$) .$

\section{RESULTS}

1) The action potential in the normal Ringer solution [Furukawa (13)]

The resting potential of the toad sartorius muscle generally ranged from -80 to -90 $\mathrm{mV}$, and the action potential from 120 to $130 \mathrm{mV}$ (Fig. 1).

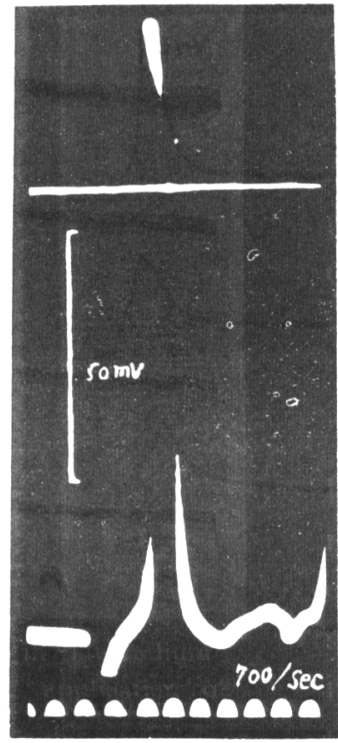

FIG. 1. Action potential of a toad muscle fiber in normal Ringer elicited by a single direct stimulus.

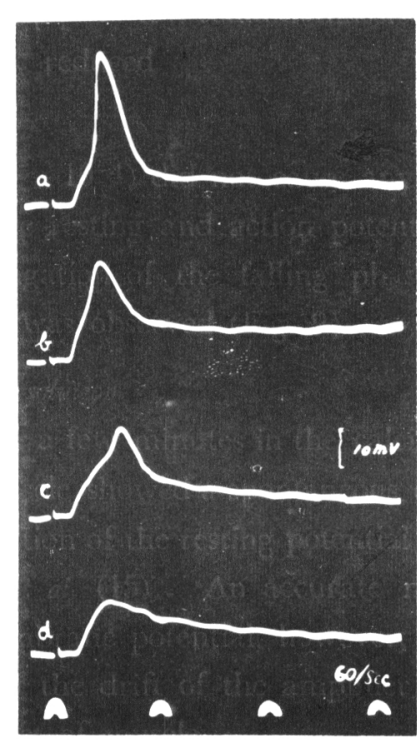

FIG. 2. Response at a single nerve-muscle junction after soaking in "low-sodium" solution.

a : 40 minutes b: 50 minutes c : 60 minutes $\mathrm{d}: 75$ minutes 
2) The e.p.p. and the effect of prostigmine

In the low-sodium blocked muscle, the resting potential did not change significantly but the action potential was reduced gradually. Thus when neuromuscular transmission was blocked, a simple e.p.p. could be picked up from a microelectrode inserted at an end-plate focus (Fig. 2).

The shape of the e.p.p. and its spatial spread have been studied by several authors. Fatt \& Katz (4) have shown that prostigmine slightly increases the amplitude of the e.p.p. and considerably prolongs its time course. Their observation was confirmed in the present experiments.

\section{3) Veratrine hydrochloride}

Veratrine in concentrations of $5 \times 10^{-7}-10^{-6}$ did not cause any appreciable change in the size of the resting potential during the periode of observation. Under this condition repetitive muscle spike potentials were evoked by a single shock on the muscle or its nerve. The frequency of the repetitive discharges was about $100 \mathrm{c} / \mathrm{sec}$ (Fig. 3A).

The e.p.p. of low-sodium muscle increased in size (Fig. 4).

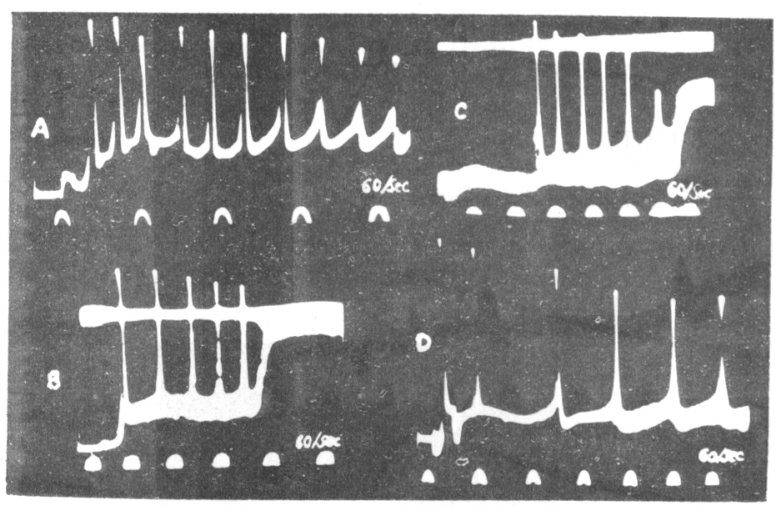

FIG. 3. Response to single direct stimulation of a toad muscle fiber treated with the followings.

A : $5 \times 10^{-7}$ veratrine

B : $10^{-5}$ aconitine

C : $10^{-5}$ veriloid

D : calcium-free solution

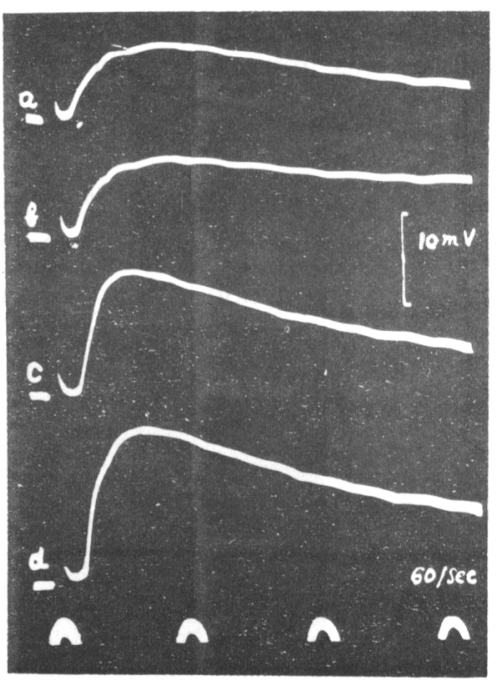

FIG. 4. The e.p.p. in "low-sodium" muscle after application of $5 \times$ $10^{-7}$ veratrine.

a: before $b$ : 5 minutes after c : 15 minutes after $\mathrm{d}$ : 30 minutes after

A higher concentration of veratrine $\left(10^{-4}\right)$ caused a blockade of neuromuscular transmission.

4) Aconitine hydrochloride

The effects of aconitine (10-5) were similar to those of veratrine.

Aconitine did not produce any significant change in the resting potential but caused repetitive muscle spike potentials following single nerve or muscle stimulation (Fig. 3B). 
The e.p.p. of low-sodium muscle gradually increased in size and reached the critical height which was sufficient to set up a propagated impulse. As with veratrine, a higher concentration of aconitine (10-4) blocked neuromuscular transmission.

5) Veriloid (Riker)

This drug is a mixture of ester alkaloids obtained from Veratrum viride. After soaking for 10 to 30 minutes in the solution containing $10^{-5}$ veriloid, a single shock on the muscle or its nerve caused a repetitive firing of the muscle fiber (Fig. 3C). Soaking for 60 minutes in this solution blocked neuromuscular transmission without an obvious change in the resting potential.

The e.p.p. of low-sodium muscle decreased in size and finally disappeared (Fig. 5).

6) Guanidine carbonate

Guanidine $\left(2 \times 10^{-4}-10^{-3}\right)$ did not bring about any significant change in the resting potential and the shape of the action potential elicited by single direct stimulation. In contrast to a direct shock, a single motor nerve volley evoked a train of repetitive discharges (Fig. 6).

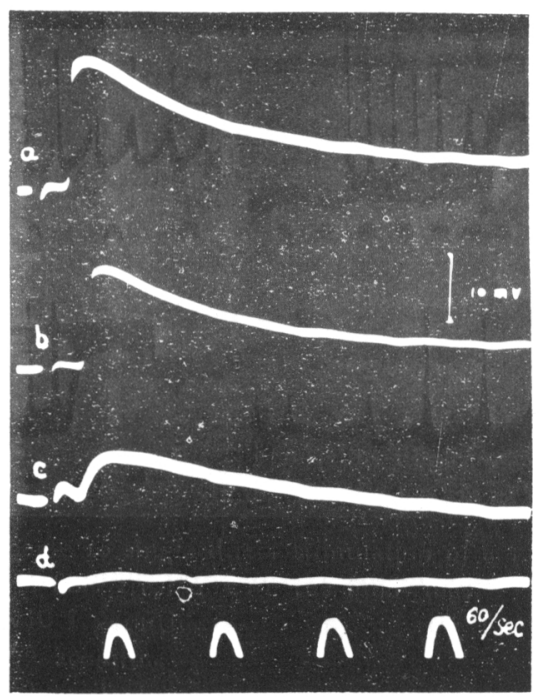

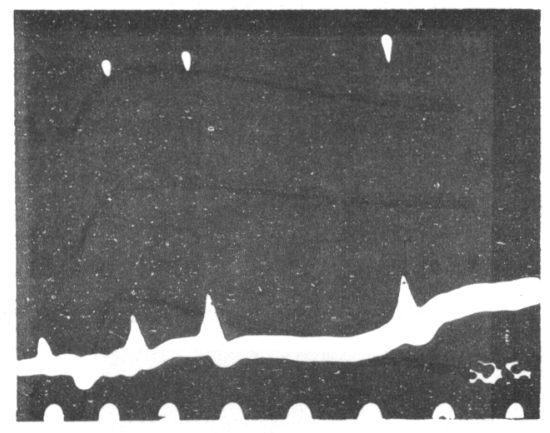

FiG. 6. Response to single nerve stimulation of a toad muscle fiber treated with $10^{-3}$ guanidine.

FIG. 5. The e.p.p. in "low-sodium" muscle after application of $10^{-5}$ veriloid.

a: before b: 5 minutes after $c: 15$ minutes after $d: 30$ minutes after

Guanidine in this concentration remarkably increased the size of the e.p.p. in the lowsodium muscle and initiated a propagated muscle spike (Fig. 7).

7) Tetraethylammonium bromide (TEA-bromide)

Hagiwara \& Watanabe (14) found that TEA-chloride brings about a marked lengthening in the time course of the action potentias of toad sartorius muscle. By the use of TEAbromide we have confirmed their observation.

TEA-bromide also markedly increased the size of the e.p.p. of low-sodium muscle. 


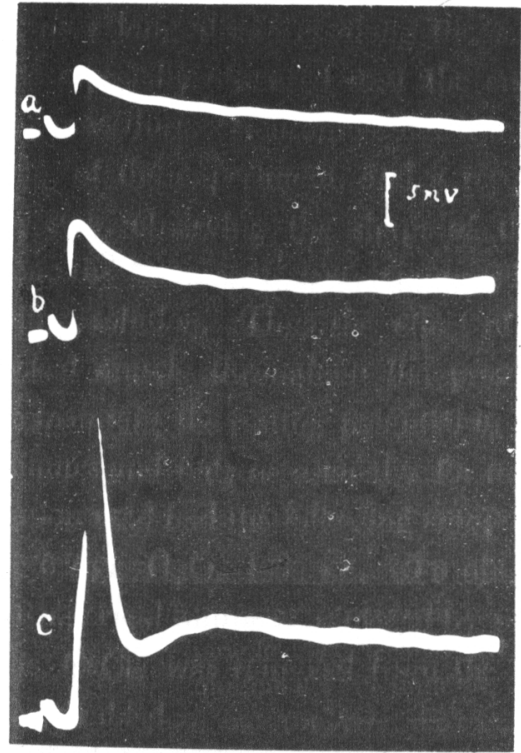

FIG. 7. Response at a single nervemuscle junction in "low-sodium" solution after application of $10^{-3}$ guanidine.

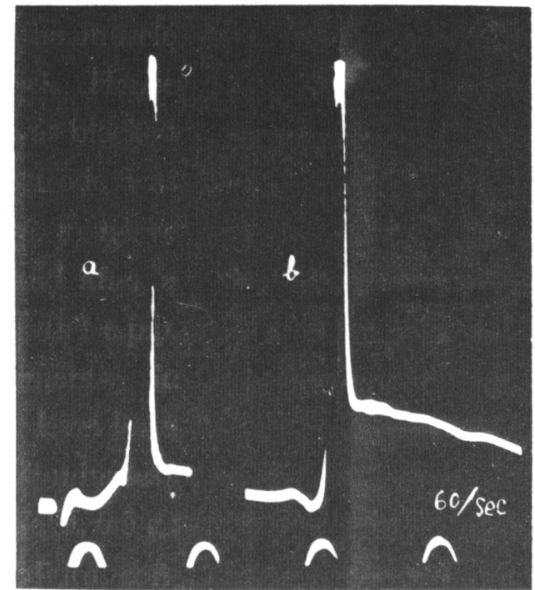

FIG. 8. Action potential of a toad muscle fiber treated with $10^{-5}$ quinine for 45 minutes.

(a) and (b) were recorded from the same fiber.

\section{8) Procaine hydrochloride}

When procaine was added to the normal Ringer solution $\left(10^{-4-}-10^{-3}\right)$, the resting potential remained unaltered, while neuromuscular transmission was gradually blocked.

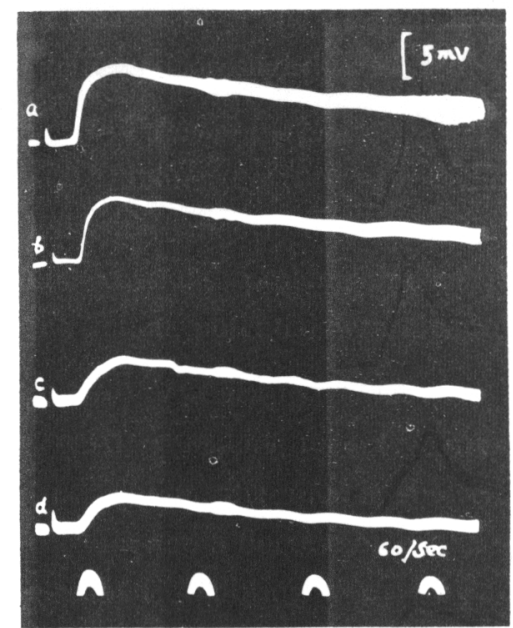

FIG. 9. The e.p.p. in "low-sodium" muscle after application of $10^{-4}$ quinine.

a: before b: 5 minutes after c : 15 minutes after $\mathrm{d}: 30 \mathrm{mi}-$ nutes after
The size of the e.p.p. of low-sodium muscle was unaffected or slightly reduced.

\section{9) Quinine sulfate}

Quinine $\left(2 \times 10^{-5}-10^{-4}\right)$ did not cause any significant change in the resting and action potentials. On occasions, prolongation of the falling phase of the action potential was observed (Fig. 9).

\section{0) Calcium-free solution}

After soaking for a few minutes in the calciumfree solution, the muscle showed a spontaneous contraction and a fluctuation of the resting potential was observed 〔Bülbring et al. (15)`. An accurate measurement of the membrane potential, however, was impossible because of the drift of the amplifier and the movement artifact of muscle.

\section{1) Copper sodium oxytartrate}

This compound was prepared in this laboratory 
according to Harnack's method (16). In the solution containing $\mathrm{CuO}^{+}$ions (pure copper : $\left.10^{-4}-4 \times 10^{-4}\right)$ a decrease in the size of the resting potential by about $20 \mathrm{mV}$ was gradually seen.

Neuromuscular transmission was blocked and the muscle fiber also failed to respond to direct stimulation. The e.p.p. of low-sodium muscle was reduced in size.

12) Caffeine

After soaking for 30 minutes in the solution containing $10^{-8}$ caffeine, the resting potential was reduced to $-60--70 \mathrm{mV}$. After 50 minutes the muscle fiber failed to respond to direct stimulation.

In a lower concentration $\left(10^{-4}\right)$, the resting potential remained unaltered for a long period and the action potential maintained its original size and time course. Occasionally, prolongation of the falling phase of the action potential was observed, which was quite similar to that observed in the muscle soaked in quinine solution. Probably it is due to the movement artifact which accompanies the characteristic muscle contraction caused by quinine and caffeine.

\section{3) Excess of potassium ion}

For the potassium-rich solution, Ringer's solution was modified by increasing $\mathrm{KCl}$ four times and lowering the concentration of $\mathrm{NaCl}$. This solution produced a rapid fall in the resting potential to $-50 \mathrm{mV}$ and made the muscle non-excitable.

\section{DISCUSSION}

The sciatic-sartorius preparation of the Japanese toad was far less sensitive to drugs than that of the English frog, and much higher concentrations of drugs were required to present their effect. It may be attributable to a specific barrier that obstructs diffusion from external media to the muscle surface.

Both veratrine and veriloid are Veratrum alkaloids. But there were considerable differences between their pharmacological activities. Veratrine exhibited a remarkable effect on the muscle fiber and a very feeble blocking action of neuromuscular transmission.

Conversely, veriloid demonstrated a less marked effect on the muscle fiber and a more potent neuromuscular blocking action.

Quinine and caffeine did not prolong the action potential as expected. It seems that the drugs which prolong the "active state" (17) of muscle do not always prolong the action potential.

Using Sugi's separated method, Ozawa (18) showed that TEA increases the size of the e.p.p. in the curarized muscle and Inano (19) demonstrated similar effects with guanidine and veratrine. Their observations were confirmed by the present authors with the intracellular microelectrode in the low-sodium muscle. However, veratrine in a higher concentration of $10^{-4}$ blocked neuromuscular transmission and reduced the e.p.p. of low-sodium muscle. 


\section{SUMMARY}

1. The effects on the membrane activities of the toad sartorius muscle of veratrine, aconitine, veriloid, calcium-free solution, guanidine, TEA, quinine, caffeine, excess of $\mathrm{K}^{+}$ion, procaine and $\mathrm{CuO}^{+}$ion were investigated with an intracellular recording electrode.

2. Veratrine produced repetitive muscle spikes when single shock stimulation was applied either to the nerve or muscle.

Veriloid, aconitine and calcium-free solution have been observed to produce such repetitive responses.

Guanidine produced repetitive muscle spikes only if a motor nerve volley was applied.

3. Veratrine, aconitine, veriloid, guanidine, quinine, TEA and procaine did not alter the resting potential. Excess of $\mathrm{K}^{+}$ion, caffeine and $\mathrm{CuO}^{+}$ion produced a marked fall in the resting potential.

4. Veratrine, aconitine, TEA and guanidine increased the size of the e.p.p. in the lowsodium muscle, whereas caffeine, quinine, veriloid and $\mathrm{CuO}^{+}$ion decreased it. Procaine was ineffective or only slightly diminished the size.

\section{REFERENCES}

1) LING, G. AND GERARD, R.W.: J. cell. and comp. Physiol. 34, 383 (1949)

2) LING, G. AND GERARD, R.W.: Ibid. 34, 397 (1949)

3) NASTUK, W.L. AND HODGKIN, A.L.: Ibid. 35, 39 (1950)

4) Fatt, P. AND Katz, B.: J. Physiol. 115, 320 (1951)

5) Del CASTIllo, J. AND StaRK, L.: Ibid. 116, 507 (1952)

6) FATT, P. AND KATZ, B.: Ibid. 117, 109 (1952)

7) FATT, P. AND KATZ, B.: Ibid. 118, 73 (1952)

8) NASTUK, W.L.: J. cell. and comp. Physiol. 12, 249 (1953)

9) Del. Castillo, J. ANd Engbaek, L.: J. Physiol. 124, 370 (1954)

10) Del Castillo, J. AND KaTZ, B. : Ibid. 124, 553 (1954)

11) HUNT, C.C. AND KUFFLER, S.W.: Ibid. 126, 293 (1954)

12) KATZ, B.: Ibid. 131, 665 (1956)

13) FURUKawa, T.: Jap. J. Physiol. 4, 268 (1953)

14) Hagiwara, S. ANd Watanabe, A.: J. Physiol. 129, 513 (1955)

15) Bülibring, E., Holman, M. AND lülllmaN, H.: Ibid. 133, 101 (1956)

16) Harnack, E.: Arch. exp. Path. u. Pharmakol. 3, 49 (1875)

17) EDWARD, E., RITChIE, J.M. AND WilkIE, D.R.: J. Physiol. 133, 101 (1956)

18) OZAwA, T.: Electro-Physiology 8, 1 (1955)

19) INANO, T.: Ibid. 8, 45 (1955) 